\title{
De lo social a lo étnico: conversación con Julio Pinto Vallejos acerca de la historia y pensamiento mapuche reciente en Chile
}

\author{
From the social to the ethnic: conversation with Julio Pinto Vallejos \\ about the recent history and thought Mapuche in Chile
}

Pedro Canales Tapia*

Patricio Macaya Bermejo

\begin{abstract}
Resumen
En las próximas líneas se desarrolla una conversación con el destacado historiador chileno Julio Pinto Vallejos, referida a un ámbito que no es su "área de especialización", como lo es la historia y el pensamiento mapuche en particular y étnico en general, con la intención de ampliar el debate respecto de los estudios y futuro de los pueblos indígenas en Chile y la región. En este sentido, creemos que la apertura de la discusión e inclusión de voces no siempre vinculadas a esta historia pero si al debate cotidiano respecto de la diversidad, pluralidad y derechos humanos, permiten tomar nota y perfilar permanentemente el trabajo de los/as involucrados/as.
\end{abstract}

Palabras claves: Historia mapuche, intelectualidades indígenas, Chile reciente, proyectos y demandas.

\begin{abstract}
In the next few lines it develops a conversation with the outstanding chilean historian Julio Pinto Vallejos, referring to an area that is not his "area of expertise", as is the history and the Mapuche particular thought and ethnicity in general, with the intention to broaden the debate on future studies and indigenous peoples in Chile and the region. In this regard, we believe that the opening of the discussion and inclusion of voices not always linked to this story but if the daily debate on diversity, pluralism and human rights, allow you to take note and permanently shape the work involved.
\end{abstract}

Keywork: Mapuche history, indigenous intellectualities, recent Chile, projects and demands.

\footnotetext{
Chileno. Doctor. Instituto de Estudios Avanzados. Universidad de Santiago de Chile. Docente Universidad Viña del Mar. E mail: pedro.canales@usach.cl; pcanales@uvm.cl

${ }^{* *}$ Chileno. Magister ( $)$. Programa de Magister en Historia. Universidad de Santiago de Chile. Profesor de Historia. Universidad de La Frontera. E mail: p.macaya01@ gmail.com

Esta entrevista es parte del Proyecto FONDECYT $\mathbf{N}^{\mathbf{0}} \mathbf{1 1 1 2 1 2 3 1}$ relativo a pensamiento indígena y descolonización.
} 


\section{Introducción}

La historia social en Chile posee varios/as exponentes. Sin duda, esta vertiente de análisis histórico ha sido prolífica en Chile, luego del fin de la dictadura militar en 1990. No obstante, antes ya se gestaban los pilares de esta. Entre los expositores más destacados figura Julio Pinto Vallejos, historiador, con raíces en el valle del Limarí, norte chileno, formado en Yale, Estados Unidos, y destacado académico de la Universidad de Santiago de Chile.

El trabajo de Julio Pinto es abundante en varios planos. En el ámbito docente, destaca la dirección de la carrera de Historia de la Universidad de Santiago durante la década de 1990 y parte de la década del 2000, y más recientemente la dirección del doctorado en Historia en esta misma universidad. En cuanto a publicaciones, sobresalen más de una veintena de $\operatorname{artículos}^{1}$ y libros que se han centrado en la historia del mundo obrero y sindical, destacando textos como la Historia contemporánea de Chile escrita junto a Gabriel Salazar, la biografía a Luis Emilio Recabarren y más recientemente El orden y el bajo pueblo, junto a otros investigadores ${ }^{2}$.

Ahora bien, ¿por qué conversar acerca de discusiones étnicas con un conspicuo representante de una vertiente historiográfica tan potente como la historia social, no especializado y familiarizado con los estudios de esta índole? ¿Qué se puede sacar en limpio de una propuesta como esta?

En este sentido, son varias las motivaciones y alcances involucrados. En primer lugar, porque siempre es un aporte conocer la opinión de investigadores sociales. En segundo lugar, porque la historia mapuche en Chile desde 1990 se ha ido instalando como parte del debate nacional. En tercer lugar, porque con los años han ido visibilizándose pensadores indígenas que han puesto en la mesa nuevos debates. En cuarto lugar, porque las

\footnotetext{
1 Ver entre otros: Pinto, Julio (2013). "Os fantasmas da Unidade Popular: Um vazio inquietante na historiografia chilena", Revista Eletrônica da ANPHLAC (Associaçao Nacional de Pesquisadores e Professores de História das Américas, Brasil), $\mathrm{N}^{\mathrm{o}}$ 14, enero-junio. ps. 31-42; http://revista.anphlac.org.br; Pinto, Julio (2012). Reseña del libro de James A. Wood, The Society of Equality: Popular Republicanism and Democracy in Santiago de Chile, 1818-1851, en American Historical Review, vol. 117, $\mathrm{N}^{\circ}$ 3, junio. p. 906; Pinto, Julio (2011). "¿La tendencia de la masa al reposo? El régimen portaliano enfrenta al mundo plebeyo, 1830-1851", Historia № 44, vol. II, Instituto de Historia, Pontificia Universidad Católica de Chile, Santiago, 2011.

${ }^{2}$ Ver Salazar, Gabriel y Pinto, Julio (1999). Historia de contemporánea de Chile. V tomos. Chile: Ediciones Lom (1999); Pinto, Julio (2013). Luis Emilio Recabarren: Una biografía histórica. Chile: LOM Ediciones; Pinto, Julio (2015). El orden y el bajo pueblo. Los regímenes de Portales y Rosas frente al mundo popular, 1829-1852, en co-autoría con Daniel Palma, Karen Donoso y Roberto Pizarro. Chile: LOM Ediciones.
} 
discusiones de corte ético debe abrir los "micrófonos" y con ello las interlocuciones, y en quinto lugar, porque la educación formal escolar debe comenzar a girar hacia nuevas semánticas y propuesta de sentido en cuanto a enseñanza de historia étnica, dejando atrás el ethos decimonónico que signó a pueblos como los mapuche como salvajes, pendencieros y viciosos, sumergidos en un entramado social caótico y bestial.

Sin duda que uno de los desafíos mayores para la comunidad de historiadores e historiadoras en Chile de cara al futuro, ha de ser el involucramiento en una discusión como la que se aborda en estas líneas, con la intención de comenzar a escribir nuevas historias, con capítulos no estereotipados y ni racializados, y más cada vez más emancipatorios en los marcos teóricos, analíticos y metodológicos. Espacios en el cual el giro epistemológico, plurinacional y descolonizador se comience a tomas la agenda de trabajo.

Por último, antes de dar paso a la reflexión dilógica con julio Pinto Vallejos, le agradecemos a este profesor por el aplomo y entereza a la hora de aceptar conversar sobre estos temas, que en lo cotidiano investigativo "no son sus temas". Consideramos que esto es una muestra de la capacidad analítica y conexión con los debates nacionales que debe poseer un historiador con la trayectoria como la del profesor entrevistado.

\section{Historia y pensamiento Mapuche}

El primer aspecto de esta conversación entrecruza varios nodos analíticos, destacando el sitio de aproximación a la historia indígena y la sensibilidad para con la figura histórica indígena. En este sentido, la situación mediática mapuche, criminalizada en los medios de comunicación y demonizada en el curriculum escolar, permiten adentrarnos en la mirada de un investigador

Profesor ¿Tiene usted alguna cercanía con el mundo mapuche o indígena en general, ya sea de índole intelectual, familiar, territorial?

Ni personal, ni familiar, ni tampoco por los estudios que he hecho. La cercanía que tengo es, básicamente, a través de alumnos o colegas que se han dedicado al tema, y también una, yo diría, postura bastante empática respecto del movimiento mapuche $\mathrm{y}$ sus reivindicaciones. Yo creo que eso incidió para que uno de mis alumnos que es Fernando Pairicán, me pidiera que presentara el año pasado su libro "Malón". Por lo tanto, mi cercanía se produce más en calidad de persona empática con su lucha que de especialista ${ }^{3}$.

A propósito ¿Qué significa para usted la presencia de personas mapuche en la academia y en especial en el mundo de la historia?

\footnotetext{
${ }^{3}$ Ver Pairican, Fernando (2014). Malón. La rebelión del movimiento mapuche en Chile, 1990-2010. Santiago: Pehuén ediciones.
} 
Que es algo muy bienvenido que tengamos a personas mapuche en el mundo de la historia, porque intelectuales mapuche ha habido siempre. Uno podría definir incluso el concepto de intelectual en un registro gramsciano, y decir que esa categoría abarca a todas las personas. Pero si nos referimos a personas con formación y con especialización en la investigación histórica, yo creo que estamos en presencia de la primera generación de historiadores mapuche con formación formal -llamémoslo así-, y creo que eso le hace muy bien tanto a la historiografía como a la política chilena. Es decir, que integrantes de la propia nación mapuche investiguen su historia, se conviertan en portavoces de lo que esta significa no solo para ellos, sino que para la sociedad chilena en general, creo que es algo muy saludable.

Es más -se me había olvidado-, dentro de estas cercanías mías hacia el mundo mapuche, está también mi condición de coordinador de la colección de Historia de LOM, y LOM se ha preocupado por cubrir lo más ampliamente posible el mundo mapuche, tanto a nivel de literatura, ciencias sociales e historia. Bajo ese contexto, me correspondió invitar, convocar y coordinar la elaboración del libro "Escucha winka", que es una de las primeras -hasta donde yo sé- obras de historiografía mapuche escritas desde historiadores mapuche 4 . Entonces también, en ese contexto, yo creo que alguna cercanía he tenido con este proceso, y creo que ha sido muy importante, no por merito mío obviamente, pero "Escucha winka" es uno de los libros de LOM que más se ha vendido. Esto habla del interés y receptividad que hay en la sociedad en general respecto de este tema.

¿Qué apreciación tiene de grupos o círculos académicos que se forman desde lo mapuche hoy en dia?

Repito, creo que es un proceso necesario y que hacía falta. Creo que es bueno tanto para el propio movimiento mapuche como para la sociedad chilena en general. Que se estén instalando los temas que ellos trabajan en el espacio de debate y que exista una construcción de conocimiento especializado desde los mapuche, es bueno no solamente para su propio desarrollo intelectual y político, sino que también para que la sociedad chilena empiece a discutir estos temas y tomárselos enserio. Porque en su condición de intelectuales -con formación de tales-, lo que ellos aportan no son solamente opiniones o juicios, sino que también es conocimiento, conocimiento de primera mano que ellos mismos -ellos y ellas- están construyendo y eso es muy saludable.

Profesor, ¿cree usted que estarían en la categoría de "intelectuales indígenas" 5 se lo comento porque, en alguna ocasión, se les ha planteado esto y ellos rehúsan a 4 Ver Mariman, Pablo et al (2006). iij... Escucha, winka...!!! Cuatro ensayos de historia nacional
mapuche y un epilogo de futuro!!! Santiago: Ediciones Lom.
5 Este debate posee varios/as expositores/as, destacando los/as siguientes: Zapata, Claudia (2007). Los
intelectuales indígenas piensan América Latina. Quito: Ediciones Abya Yala; Zapata, Claudia (2014). 
entrar en tal categoría. ¿Qué opinión tiene usted de eso, de esta categorización? Y ¿Por qué lo rehúsan?

Los argumentos son variados. Principalmente por el hecho de que para ellos, la categoría de "intelectuales" es una cuestión totalmente occidental. Algunos plantean que la intelectualidad ya existía desde mucho antes de la academia. Como te decía antes, creo, siguiendo la línea gramsciana, que toda persona es un intelectual, en el sentido de que toda persona piensa, razona, reflexiona, debate, y eso ya es una labor intelectual. No hay ningún ser humano que no sea intelectual. Yo parto por eso. De manera que el rechazo de la categoría creo que es un poco exceso de purismo. Ahora, si estamos hablando del intelectual como de alguien que se ha formado de manera sistemática para trabajar en el mundo del pensamiento y de la investigación, de la creación de conocimiento, creo que también es una categoría universal, o sea, cualquier persona que tenga esta función social, es un intelectual, y eso no está reducido a la academia.

Todos los pueblos, incluyendo los pueblos originarios latinoamericanos, han tenido sus intelectuales. Como te digo, no soy un conocedor muy profundo de la cultura mapuche, pero entiendo que la función de los weichafe era y sigue siendo esa. Es decir, la de alguien que dentro de la comunidad se especializa un poco en la construcción de conocimiento, en el arte de debatir, de enseñar. Y eso es ya un intelectual. Por lo tanto, no estoy seguro de que sea una construcción occidental. Creo que es un componente de toda sociedad humana y creo también que es un componente positivo, porque cualquier actividad se enriquece en la medida en que haya personas que se especializan y se dedican de manera sistemática a trabajarla, y eso no excluye a la creación intelectual. Entonces tal vez ellos tengan motivos políticos más concretos para adoptar esta postura. Pero desde una óptica netamente conceptual yo diría que sí son intelectuales y a mucha honra.

Recién comentaba el texto "Escucha winka”, que justamente posiciona el debate de la descolonización en Chile. ¿Qué le parece a usted este debate acerca de la descolonización? Y de la mano de esto, ¿se puede hablar de colonialismo y neocolonialismo desde la sociedad chilena hacia los mapuche?

Sin duda. A ver, creo que el debate mismo es algo que nos hace bien como sociedad, y esto no es un debate nuevo. Esto es algo que se viene debatiendo desde la primera llegada de los españoles a Chile, y que se viene desarrollando en un sentido político pero también militar. Yo creo, incluso, que nunca ha desaparecido ni la realidad de la colonización ni la discusión al respecto. Y creo también que en Chile somos muy buenos para ocultar los temas importantes, para no asumirlos, pero nunca ha estado ausente el debate sobre,

Intelectuales indígenas en Ecuador, Bolivia y Chile. Quito: Abya Yala. Canales, Pedro y Rea, Carmen (2013). Claro de luz. "Intelectualidades indígenas" y descolonización en Abya Yala. Siglos XIX y XX. Santiago: IDEA-USACH.

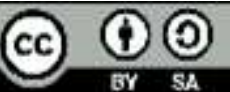


digámoslo claramente, el subyugamiento del pueblo mapuche y su natural reacción de tratar de liberarse de esto. Entonces si tú me preguntas si hay colonialismo en Chile, sin duda que lo hay, y lo ha habido desde que llegaron los españoles, o antes incluso. Uno podría pensar, en este sentido, en el colonialismo incásico frente al mundo mapuche. Y creo por tanto que es bueno que la sociedad chilena se sincere y asuma este problema como un problema que no está resuelto y que no va a estar resuelto mientras no se restituya al pueblo mapuche de todos los derechos que tiene para existir como tal.

Desde el ámbito de la historia, ¿qué opinión tiene respecto de la historia oficial que se ha construido sobre los pueblos indígenas en Chile?

Yo creo que a esta altura es una historia social bastante vapuleada. Ya casi como que nadie habla de la "pacificación de la Araucanía", para que veas tú. Eso es algo que cuarenta años atrás era parte del sentido común histórico chileno y ahora no lo es, y creo que eso es bueno y es a la vez un producto obviamente de la labor del propio movimiento mapuche, de todos estos intelectuales mapuche de los que estamos hablando. Pero también de intelectuales no mapuche que se han puesto en una actitud de apoyo y de empatía con los movimientos. Estoy pensando en gente como José Bengoa, Jorge Pinto, Rolf Foerster y tú mismo refiriéndose Pedro Canales-, que siendo winkas todos ellos, han adoptado una postura de apoyo y de colaboración no sólo discursiva, sino también de su propio trabajo intelectual con esta causa.

Entonces creo que esa visión, esa historia oficial ha perdido su condición de tal, incluso a nivel de la educación pública nacional. Ya no se habla de la "Pacificación" ni se tienen esos estereotipos, y creo que eso nos hace bien como sociedad, y creo, al mismo tiempo, que un mérito importante en esto le corresponde justamente a los intelectuales mapuche de quienes hablábamos antes. El concepto de historia oficial es ahora incluso al revés te diría yo. Que ahora quienes insisten en reponer esas imágenes- como Sergio Villalobos-, son los que tienen un poco que nadar a contracorriente. Es decir, ahora los que tienen que dar explicaciones son ellos, y eso es una buena señal. Es una señal de que hay una lucha hegemónica que se está ganando.

\section{Mirada étnica latinoamericana}

Pasando a un tema más continental, en relación a las luchas indígenas que se han dado en los últimos veinte años en el continente, por ejemplo en Bolivia, Ecuador, México ¿Cuáles serían las diferencias más significativas -guardando las proporciones-, a la hora de hacer una comparación entre la situación del movimiento indígena en Chile y en estos países?

A ver, de nuevo hablo desde una posición más bien de observador y de ciudadano que de especialista. Bueno, como tú dices, guardando las proporciones (ya que las proporciones 
son un elemento importante), no es lo mismo Bolivia o Ecuador que Chile, incluso en términos numéricos. Cuando uno mira un proceso como el que se está viviendo en Bolivia, donde sin duda las reivindicaciones de las luchas indígenas han alcanzado un estado mucho más avanzado en comparación con nosotros, al punto de que ya se ha asumido política y constitucionalmente la centralidad de los pueblos indígenas en el funcionamiento de ese Estado, y donde se les reconoce una serie de derechos y de espacios y de libertades (yo diría que tal vez ese es el caso más logrado de reivindicación política desde el mundo indígena). En comparación con eso, claro, nosotros acá estamos bastante lejos.

Otro elemento, que no sé qué tan importante sea, es que en Chile, territorialmente hablando, se ha tendido a acotar las luchas mapuche a la zona de la Araucanía, a la zona de la frontera, cosa que yo creo que a esta altura es un poco artificial porque, numéricamente, hay más mapuche en Santiago o en las grandes ciudades que en la frontera. Pero cuando se levantan reivindicaciones de tipo territorial, siempre el ojo está puesto en ese territorio. En otras partes, como Bolivia en particular, como Ecuador, o como México, lo indígena atraviesa todo el territorio y toda la sociedad, entonces es imposible hacer una separación llamémoslo así-, "ya, hasta aquí va a llegar lo indígena, hasta acá va a llegar lo no indígena".

Creo que esto, para esos países es bueno, porque debe asumirse lo indígena como propio, como parte de la construcción social e identitaria de la sociedad, que es lo que se ha hecho en Bolivia, creo yo. Ahora, no sé si esto esté garantizado de por vida, pero por lo menos en los últimos veinte años con la instalación del Estado plurinacional, hay un reconocer un asumir por parte de la sociedad que esta es una sociedad con mayoría indígena y que, por cierto, los indígenas tienen todo el derecho y el deber de hacerse cargo de la conducción de esa sociedad y de la toma de decisiones.

Aquí en Chile yo me temo que por estar más acotado territorialmente el movimiento, puede que eso facilite una postura un poco prescindente de parte del resto de la sociedad, es decir, se tiene la idea como de que esto no es un problema nuestro, de que es un problema de la frontera, de la Araucanía, y entonces que lo arreglen allá, porque qué tengo que ver yo en esto. Y la verdad es que todos tenemos que ver, y es bueno que eso se vea así. En ese sentido, creo que puede ser un inconveniente en el caso nuestro esta territorialización de los movimientos. Se piensa que es la Araucanía, que es el norte Aymara, que es Rapa Nui... pero no que es la sociedad chilena en general, en circunstancias en que yo creo que sí es la sociedad chilena toda.

¿Qué papel cree que juegan y deberían jugar estos intelectuales indígenas en las diferentes reivindicaciones y expresiones del mundo indigena?

Bueno lo que yo veo es que están jugando un papel fundamental, es decir, su obra no es una obra prescindente, meramente academicista que está separada de las luchas políticas. Al 
contrario. Todos estos intelectuales indígenas de quienes estamos hablando, y no sólo los historiadores, también los poetas, los sociólogos, los antropólogos, etcétera, son parte también de los movimientos de liberación indígena. Y en buena hora, porque alimentan estos movimientos con su propia reflexión, con su pensamiento, con los resultados de sus investigaciones y todo eso por un lado hace que las demandas vayan acompañadas de contenido y de una densidad importante. Pero también creo que tiene un efecto de autovaloración de parte de los propios integrantes de las naciones indígenas. Esta sensación de que "mira nosotros también somos capaces de producir pensamiento, de debatir de tú a tú con cualquiera que se nos ponga por delante", y eso tiene un efecto de dignificación.

El año pasado tuve el privilegio de ser invitado a un encuentro de profesores mapuche en el sur, y ahí uno de los expositores comentaba que cuando era menor o joven, sus compañero de etnia, sus hermanos, ocultaban y se avergonzaban de su condición de mapuche, y que eso se había revertido de manera importante en el momento en que empiezan a ver a personas mapuche asumiendo posiciones de debate, de conducción, de creación de conocimiento al mismo nivel que cualquiera. Entonces esta persona (cuyo nombre no recuerdo), decía, que para él fue muy edificante, muy importante, porque lo hizo darse cuenta de que, bueno, ellos también pueden hacer esto, y no tienen por qué estar ocultando su condición, porque su condición es algo digno de orgullo.

Con respecto a estas voces de autonomía que han surgido y que están presentes en la actualidad ¿Qué apreciación tendría usted particularmente de esta demanda, y cuál sería el camino que usted recomendaría seguir para lograr una coexistencia adecuada entre el estado, la sociedad chilena y el mundo mapuche?

A ver, yo no soy quien para recomendar nada. Yo creo que eso es algo que depende del propio movimiento y también sé que hay muchos matices y muchas sutilezas. Es decir, que este es un tema muy complejo. Yo recuerdo la conclusión del "Escucha winka", donde los autores toman una posición bastante, se podría decir, sofisticada respecto de este tema. Pero entiendo que hay posturas más rupturistas que esa, y posturas menos rupturistas. En fin, mi percepción, bueno, primero que nada, es que no se va a resolver la cuestión indígena hasta que no se reconozcan plenamente todos los derechos que los pueblos originarios tienen, tanto políticos, culturales, económicos, territoriales, etcétera. Eso yo creo que es un piso mínimo.

Ahora, que esto se traduzca en una separación total (olvidémonos de las otras etnias por el momento y refirámonos sólo al pueblo mapuche), que se cree un estado mapuche separado del Estado chileno, lo que personalmente creo es una demanda legítima, me pregunto más bien si políticamente es un escenario viable. Y hablo incluso pensando en que la zona de la frontera en una zona donde conviven mapuches y winkas, entonces me pregunto bueno ¿qué va a pasar con esa población winka si se crea un Estado mapuche? Eso ya le da una complejidad. Sin considerar la previsible resistencia que va a tener el Estado chileno, la 
clase política chilena de permitir una cosa así. Por tanto, más que cuestionarme la legitimidad de esa demanda, que yo creo que la tiene, creo que el debate podría ir por el lado de la viabilidad, es decir, pensar qué tan factible es que ocurra algo así. Y en ese contexto, entendiendo que no va a ser algo fácil. Tal vez experimentar con modalidades de autonomía parciales sería por lo menos un avance con respecto a lo que hay ahora. Estoy pensando en un esquema como el de la autonomía española, donde se reconozcan ciertos derechos de todo tipo en ciertos espacios, y donde los indígenas conduzcan un poco el proceso y tomen las decisiones sin significar necesariamente una ruptura con el Estado nacional.

Repito, yo ahí no tengo una posición de principios, porque finalmente la ocupación de la Araucanía por el Estado chileno fue un acto de fuerza, y por tanto y desde mi punto de vista, no tiene ninguna legitimidad. Fue, más bien, algo en lo que se obligó a sus habitantes a someterse por una cuestión de fuerza, de quien tiene más capacidad para imponer la violencia. Por eso quiero insistir una vez más, y a riesgo de ser majadero, que no estoy poniendo en cuestión la legitimidad de esa demanda. Pero sí... porque a veces hay demandas legítimas que si no tienen los elementos suficientes como para sostenerse terminan convirtiéndose en un factor de frustración.

En ese contexto pienso yo que tanto para los pueblos originarios, como para la sociedad chilena en general, una salida intermedia, tipo autonomías a la española, podría ser por lo menos un adelanto respecto de lo que tenemos ahora. No una solución definitiva sin duda, porque por otro lado también hay que decirlo, ha habido a la inversa, un proceso de, no quiero decir de asimilación, pero sí de inserción de la población mapuche en la sociedad chilena que tampoco va a ser fácil de desarmar. Por ejemplo, hablamos igual, la formación educacional que han tenido los mapuche (y ya varias generaciones), guarda relación con la nación chilena, y finalmente por poner un ejemplo caricaturesco, winkas y mapuche apoyan a la selección chilena en los partidos de fútbol.

Entonces hay elementos de cohabitación, de convivencia que son difíciles de deshacer por decreto, y tal vez un esquema de autonomías pueda ayudar a ir suavizando esas aristas y haciendo más saludable y sana esta convivencia. Pero reitero que hablo desde una posición de ignorancia. Seguramente alguien más metido en las reivindicaciones del movimiento mapuche me podría refutar todo lo que yo estoy diciendo. Pero si tú me preguntas ahora como veo yo la cosa, yo la veo por ahí. La alternativa, es una alternativa complicada. La alternativa de ruptura violenta, de guerra civil, no sé si esa sea la salida más aconsejable.

\section{Conclusión}

La conversación con el profesor Julio Pinto arrojó a la mesa temas trascendentes en el debate acerca de los pueblos indígenas, y en particular sobre el mundo mapuche, desde la vereda de la historia y las ciencias sociales. Tales temas tiene que ver con ejes, ligados 
entre sí, que abordan principalmente el papel de los mapuche en el mundo de la academia, y de la historia principalmente, además de rol que ellos están cumpliendo en labores de reivindicación política de la nación mapuche.

Al respecto Pinto destaca la presencia de una "primera generación de historiadores mapuche con formación formal", quienes están investigando y trabajando su propia historia como pueblo-nación, los que de la mano con otros pensadores indígenas (poetas, sociólogos, antropólogos, entre otros), van posicionando discusiones y aumentando el nivel de impacto de las mismas en la sociedad chilena, tomando cierta ventaja en la lucha hegemónica librada con la vieja historia oficial.

Tomando en cuenta lo anterior cabe interrogarnos, ¿estamos en presencia del comienzo del fin de una historia oficial?, ¿acaso las bases de la tradición historiográfica chilena están siendo -realmente- sacudidas por la irrupción de historiadores y pensadores indígenas?, o ¿será acaso solo una inclusión simbólica y discursiva en el mundo de la historia, sin rasgos realmente vinculantes?

El tema del colonialismo es abordado y reconocido por Pinto, señalando que es una situación que se extiende y va a permanecer hasta que no se restituyan al pueblo mapuche de sus derechos políticos, culturales, económicos y territoriales. El reconocimiento de derechos podría ser el comienzo de una salida intermedia al conflicto, abogando (o simpatizando) por un sistema de Autonomías parciales, como una alternativa en donde los mapuche conduzcan el proceso y tomen decisiones en el mismo. Sin embargo, destaca que cualquier alternativa debiera prestar atención al proceso de inserción de los mapuche en la sociedad chilena, cuestión que va de la mano con lo que el profesor Pinto señala como una artificialidad de la territorialización de las luchas mapuche, que circunscribe estas solo a la Frontera. Lo anterior facilitaría una postura prescindente de lo mapuche en la sociedad chilena, sin tomar en cuenta que el grueso de la población de este pueblo estaría en Santiago. Para Pinto lo indígena debiera asumirse en la construcción social e identitaria de la sociedad, lo que convoca a preguntarse ¿Quiénes serían los actores y la(s) instancia(s) para esta construcción social e identitaria inclusiva de lo indígena?, ¿será acaso que las esperanzas debieran estar en el renuevo generacional de las historiadoras e historiadores, y en general de quienes piensan y trabajan en función del estudio de la sociedad?

Las palabras de Pinto sin duda representan un buen augurio. La empatía que declara resulta ser una buena señal para la construcción y ampliación de un puente, que de apoco vaya conectando las diferentes historias, chilena y mapuche, que sin duda están estrechamente relacionadas. Este puente abriría el paso y un espacio a las voces mapuche en el mundo del quehacer historiográfico, y en general de las ciencias humanas.

La importancia, a nuestro juicio, de dar tribuna a estas voces, radica en que están ocupadas apuntando a la construcción de una historia desmarcada y liberada del peso de interpretaciones historiográficas coloniales, con cargas ideológicas inferiorizadoras, 
apostando a la construcción de un futuro como pueblo-nación, sobre la base de una experiencia vivida; su propia historia.

Recibido: 24 abril 2016 Aceptado: 30 mayo 2016

\section{Bibliografía}

Canales, Pedro y Rea, Carmen (2013). Claro de luz. "Intelectualidades indígenas" y descolonización en Abya Yala. Siglos XIX y XX. Santiago: IDEA.

Mariman, Pablo et al (2006). !!!... Escucha, winka...!!! Cuautr ensayos e historia naconal mapuche y un epilogo de futuro. Santiago: Ediciones Lom.

Pairican, Fernando (2014). Malón. La rebelión del movimiento mapuche en Chile, 1990-2010. Santiago: Pehuén ediciones.

Pinto, Julio (2011). "¿La tendencia de la masa al reposo? El régimen portaliano enfrenta al mundo plebeyo, 1830-1851", Historia No 44, vol. II, Instituto de Historia, Pontificia Universidad Católica de Chile, Santiago.

Pinto, Julio (2012). Reseña del libro de James A. Wood, The Society of Equality: Popular Republicanism and Democracy in Santiago de Chile, 1818-1851, en American Historical Review, vol. $117, \mathrm{~N}^{\circ} 3$.

Pinto, Julio (2013). "Os fantasmas da Unidade Popular: Um vazio inquietante na historiografia chilena", Revista Eletrônica da ANPHLAC (Associaçao Nacional de Pesquisadores e Professores de História das Américas, Brasil), No 14, enero-junio. ps. 31-42; http://revista.anphlac.org.br;

Pinto, Julio (2013). Luis Emilio Recabarren: Una biografía histórica. Chile: LOM Ediciones.

Pinto, Julio (2015). El orden y el bajo pueblo. Los regímenes de Portales y Rosas frente al mundo popular, 1829-1852, en co-autoría con Daniel Palma, Karen Donoso y Roberto Pizarro. Chile: LOM Ediciones.

Salazar, Gabriel y Pinto, Julio (1999). Historia Contemporánea de Chile, en co-autoría con Gabriel Salazar; tomos 1 y 2. Chile: LOM Ediciones (tomos 3, 4 y 5, LOM Ediciones, Santiago, 2002).

Zapata, Claudia (2007). Los intelectuales indígenas piensan América Latina. Quito: Ediciones Abya Yala.

Zapata, Claudia (2014). Intelectualidades indígenas. Quito: Abya Yala.

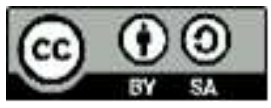

